\title{
UM ESTUDO DOS SENTIDOS DO SER E DO ÉTHOS EM PARMÊNIDES A PARTIR DA FILOSOFIA DE MARTIN HEIDEGGER
}

\section{A STUDY OF THE WAYS OF BEING AND ÉTHOS IN PARMENIDES FROM THE PHILOSOPHY OF MARTIN HEIDEGGER}

Pedro Proscurcin Junior*

\begin{abstract}
RESUMO
O presente artigo tem por escopo estudar os fragmentos 2 e 7 do texto de Parmênides a partir da filosofía de Martin Heidegger. O estudo volta-se para o entendimento dos caminhos investigativos do ser e do sentido encobridor do termo éthos no poema. Ao fim, é comparado o sentido estabelecido por Parmênides com o verificado nos fragmentos de Heráclito, que se mostra mais originário, como podemos entender através dos textos de Heidegger.
\end{abstract}

PALAVRAS-CHAVE: Éthos. Ser. Parmênides. Heráclito. Heidegger.

\begin{abstract}
The article aims to study the fragments 2 and 7 of Parmenides through Martin Heidegger's philosophy. The study focuses on the comprehension of the Being's investigative paths and on the covered-up sense of the term éthos in the poem. Finally, the text is going to compare the sense of éthos established in Parmenides with the one verified in Heraclitus. The last one shows itself much more original, as can be understood from Heidegger's texts.
\end{abstract}

KEY-WORDS: Éthos. Being. Parmenides. Heraclitus. Heidegger.

\footnotetext{
* Doutor em Filosofia pela Universidade de Bonn (Alemanha). Professor do Programa de Pós-Graduação em Filosofia da PUC-SP. Pós-doutorando na Universidade Alberto Hurtado (Chile), com bolsa do CONICYT (Ministério da Educação do Chile).
} 


\section{Introdução}

Em seu livro Parmênides, Martin Heidegger empreende uma inovadora análise do primeiro fragmento do poema parmenídico (frag. 1, 22-32) ${ }^{1}$ (HEIDEGGER, 1982, p. 1-23), no entanto, ainda são pouco estudadas suas interpretações sobre outros fragmentos. A partir do pensamento heideggeriano, o presente texto fará uma leitura de dois fragmentos do poema de Parmênides ${ }^{2}$ e buscará compreender a mudança do sentido do termo ethos nesse momento do pensamento grego sobre o ser. Com o texto grego em mãos, analisaremos em que medida a interpretação heideggeriana oferece novas possibilidades de entendimento ao termo que funda as acepções de "costume" e "hábito" na filosofia. Ao fim, verificaremos o quanto o termo " ${ }^{\prime}$ Oos (éthos), agora grafado com épsilon $(\varepsilon)$, modificou o seu sentido, em contraste com o

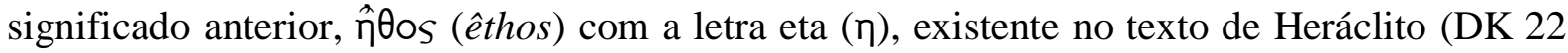
B119).

\section{Duas vias de investigação no poema de Parmênides}

Para melhor compreendermos o sentido do "̌tos em Parmênides, é necessário uma breve visita ao contexto existente logo no início do poema. No fragmento 2 , é exposto uma das vias de investigação a se pensar. Por isso, torna-se importante analisarmos o segundo fragmento do poema, que explica os caminhos de investigação a serem pensados. Tais caminhos são assim descritos:

Frag. 2

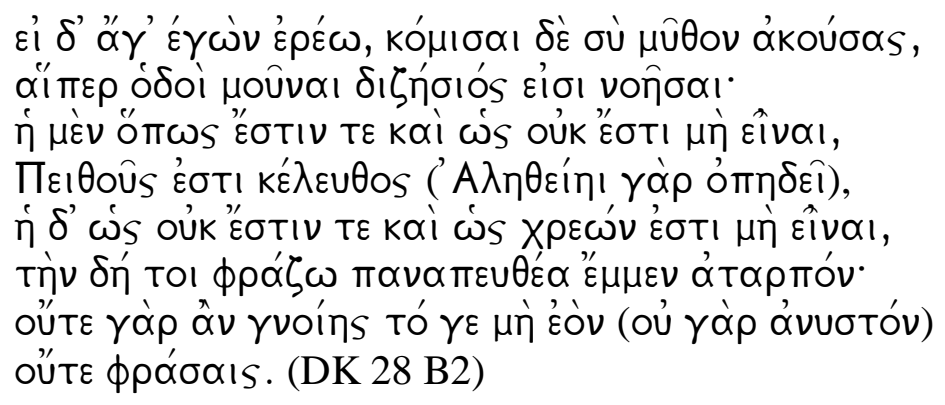

\footnotetext{
${ }^{1}$ No presente texto utilizarei, assim como fez Heidegger, de fragmentos numerados por Diels e Kranz (1951). As traduções dos fragmentos gregos e dos textos de Heidegger são minhas.

${ }^{2}$ Aqui também não nos preocupamos com aspectos formais que envolvem o poema de Parmênides (escrito em hexâmetro dáctilo) e nos atemos à análise do texto grego, deixando-o falar.
} 


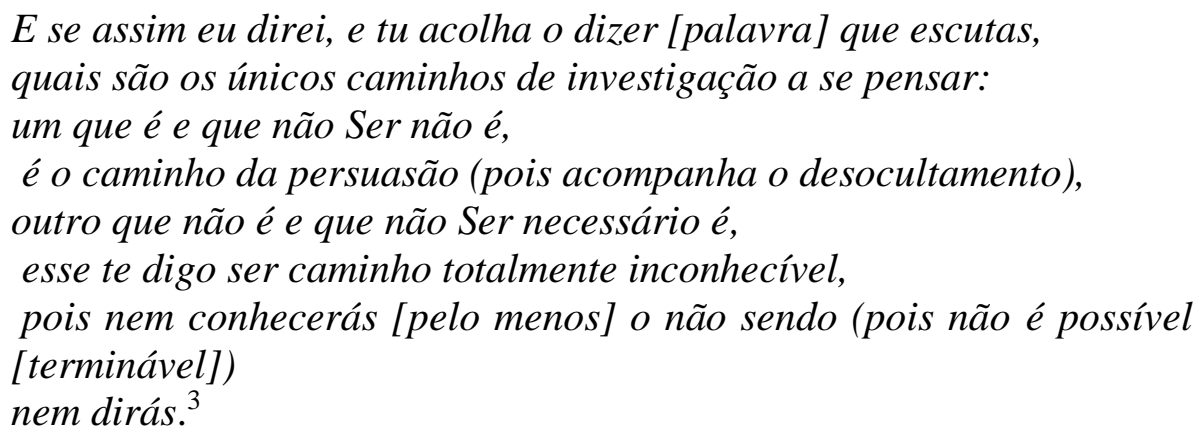

O poema de Parmênides evoca uma mensagem. Em seu poema, é descrito como um

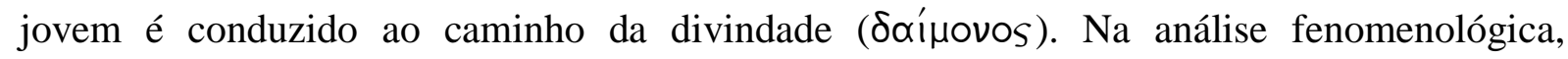
ultrapassa-se a questão que gira em torno a saber se a divindade conduz o jovem ou se é o caminho $^{4}$. O que importa é que a divindade tende a explicar o que supera a capacidade de entendimento. Daí o poeta mencionar a divindade (o "imponderável”) como aquela que "pega com sua mão" a mão direita do jovem. Trata-se da deusa $\delta^{\prime}$ kn, agora corporificada, para melhor ser entendida. A deusa literalmente pega "a mão" (i் Xદíp) do jovem . A palavra

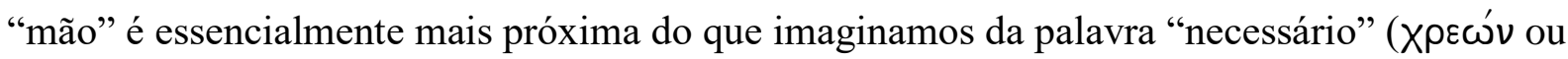
$\chi \rho \eta ́)$, que também aparece em alguns fragmentos importantes do poema ${ }^{6}$. Heidegger percebeu

\footnotetext{
${ }^{3}$ Tradução livre que busca enfatizar os sentidos do ser. Importante verificarmos nessa tradução as diversas

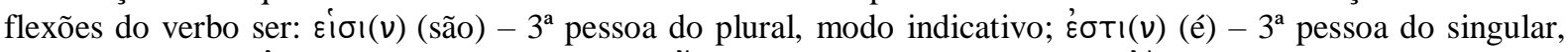

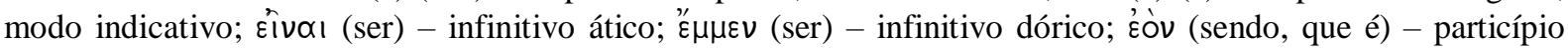

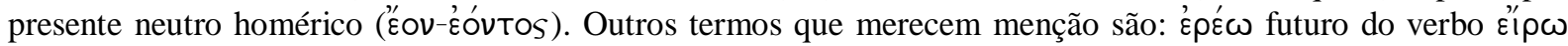

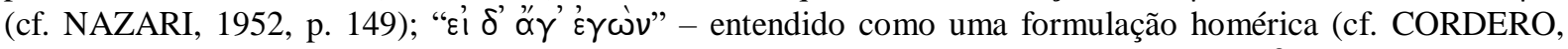
2005, p. 53-54), por isso fizemos uma tradução que entendemos mais próxima ao sentido; $\mu \hat{v} \theta$ ov (dizer, recolher, deixar ver) - acusativo singular, no nominativo é $\mu \mathrm{u} \theta$ os e sua tradução assemelha-se à $\lambda o ́ \gamma o s$, só que remete-se

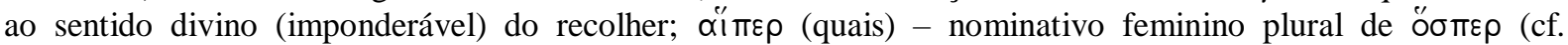

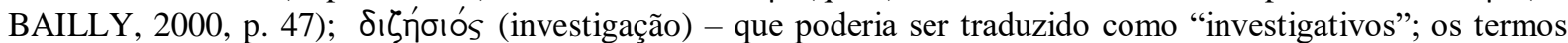
"í $\mu \dot{\varepsilon} v$ " e "i $\delta$ " indicam "por um lado" e "por outro", no caso optamos por "um" e "outro" e ambos regidos por

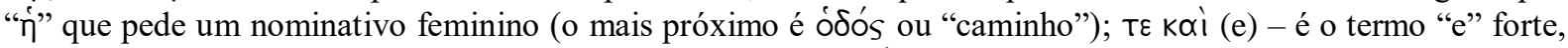

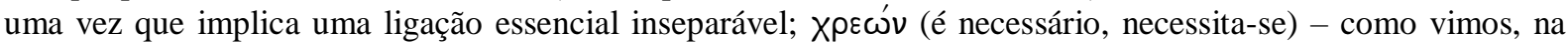

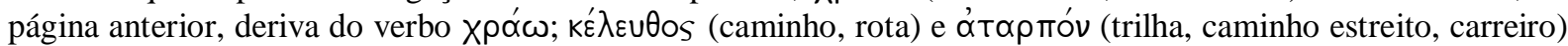
- trata-se de formas diferentes de expressar o sentido que entendemos como caminho, a primeira palavra, trata de caminhos abertos (em Homero: "os movimentos dos ventos anunciados pelo mar", Od. V, 383) e a segunda, trata do carreiro ou do caminho habitual (marcado pelo hábito, não êthos), já aberto.

${ }^{4}$ Como podemos observar junto a palavra $\delta \alpha i ́ \mu \omega v$ em Heráclito (DK B119), a divindade é o "imponderável" ou, com os devidos alertas, o "fantástico ou extraordinário". Por isso, Parmênides está preocupado com o que movimenta o jovem em direção ao caminho (ỏó́v). Isso que já o movimenta encontra o resultado na formulação de que o que lhe conduz é a divindade, ou o próprio caminho ou até os cavalos. Na verdade o espanto com a descoberta desse agir leva o poeta à questão do que o faz pensar. Isso é algo que explica a existência e, portanto, é atribuído como "divino".

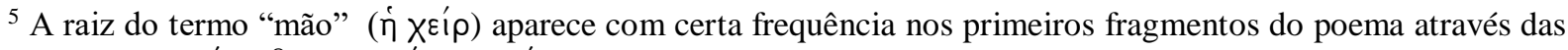

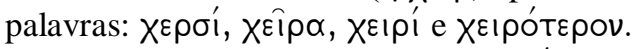

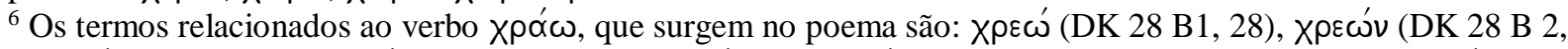

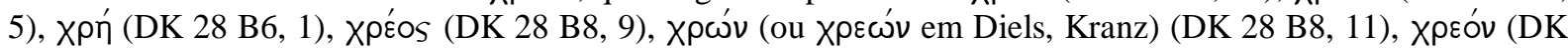

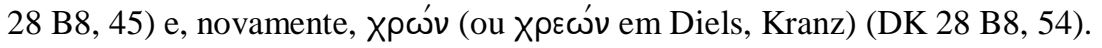


muito bem isso e extraiu da raiz do termo "mão" o sentido originário de "necessário" necessário pede a essência e, assim, pode ser entendido como existente. O necessário explicará o existir do que é, a partir do que é dado ou existe ${ }^{8}$.

No segundo fragmento do poema, haviam sido indicados os "únicos caminhos" (ódoì noûvaı) a se pensar. Tais caminhos coexistem e indicam possibilidades a se seguir. Ambos caminhos têm um caráter desvelador, só que um deles é o mais desvelador. O que ocorre é que o caminho "necessário" não é o da crença ou da persuasão ou sedução ( $\pi \varepsilon i ́ \theta \omega)$.

A interpretação generalizadora dos fragmentos de Parmênides permite a visão redutora do pensador a mero fundador da lógica, separando o caminho da verdade e o opiniático (fora da lógica que dá cientificidade). Em Heidegger verificamos a possibilidade de pensarmos que os caminhos são os de busca, investigação, pesquisa, que incentivam o pensar e o re-pensar das coisas. O convencimento nasce do des-ocultamento do entulho encobridor das verdades do caminho.

Caminhos são aqui apresentados pela deusa. Por isso ela usa o "recolher" (permitir

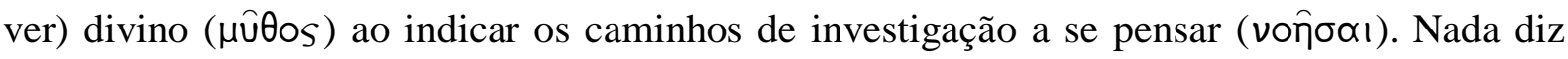
que são caminhos "opostos" ou que não podem coexistir. Todavia, o caminho mais elevado é

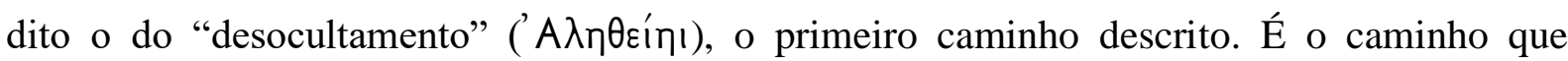
afirma que "é e que não Ser não é” e, explica-se como "o caminho da persuasão (pois

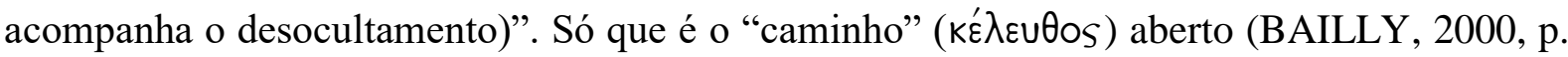
1076), não trilhável ou demarcável. Trata-se do caminho do desencobrimento, que desvela o "não Ser" como o que não é e que não encontra limites na capacidade de ser explicado. Por

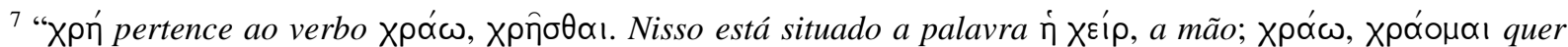
dizer: eu manejo e conservo (mantenho, fico com) para mim desta maneira na mão, eu uso, eu utilizo (brauchen

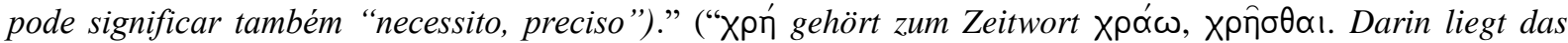

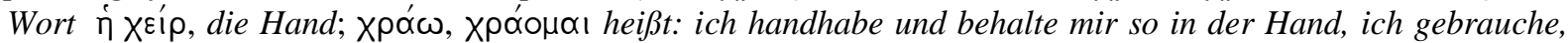
ich brauche."). Em seguida Heidegger afirma: "Necessitar (utilizar) é: deixar entrar em a essência, é defesa na essência" ("Brauchen ist: Einlassen in das Wesen, ist Wahrung im Wesen."). E conclui: "Por isso, nós

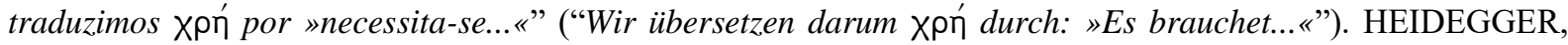
1984, p. 114-115.

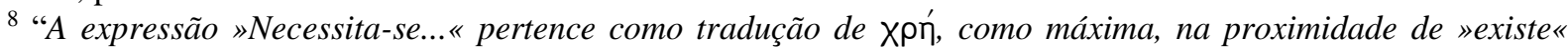
("ter-se" ou "dar-se")." ("Die Wendung »Es brauchet "gehört als Übersetzung des Xp门' im Spruch eher in die Nähe von »Es gibt«."). Essa proximidade, todavia, pode ser contrária: “O »existe" nomeia manifestamente o exato contrário de »necessita-se«; então, o que necessita, tem sim, e deseja »ter «, e pode, precisamente, não »dar«. Entretanto, quem ainda alega isso, já esqueceu novamente que, no mais elevado sentido de necessitar, o admitir ("deixar entrar") está situado na essência e ali [nisso] permanece." (“»Es gibt « nennt offenkundig das genaue Gegenteil zum »Es brauchet «; denn das, was brauchet, muß doch und möchte »haben « und kann gerade nicht »geben«. Wer indessen noch solches vorbringt, hat schon wieder vergessen, was im hohen Sinn des Brauchens liegt: einlassen ins Wesen und darin wahren.”). Então, é concluído: “»Necessita-se..." quer dizer essencialmente como isto é preciso (ou necessário)." (“»Es brauchet... «meint Wesentlicheres als: es ist nötig."). HEIDEGGER, 1984, p. 116.
} 


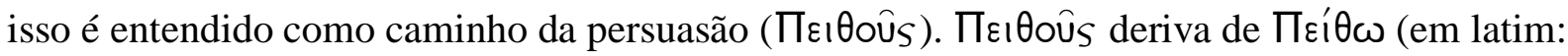
fĩdēs, fìdō). Seu sentido não é apenas de "persuasão" ou "eloquência", o que invoca um sentido de racionalidade e logicismo atual. Na verdade, $\Pi \varepsilon i \hat{\theta} \omega \omega$ invoca algo que ultrapassa tal sentido. O termo quer dizer também "com-prometer-se", "acreditar em" ou "circunvir"9. Aponta um caminho aberto que promete o encontro com algo. Tal caminho promete algo, por isso nos "seduz", nos "estimula" ou "excita"10. O termo Пعí $\omega \omega$ indica um caminho que pode tanto nos "enganar", como nos "surprender". Isso ocorre justamente porque, ao desvelar, não sabemos o que pode estar oculto ou velado e não sabemos se conseguiremos desocultar. O não Ser não é e, por ainda não ser, pode ser desvelado e, então, entendido. O não Ser, em que pese poder ser desvelado, é. A copertinência é natural ao caminho ${ }^{11}$. Ao "pôr em movimento" a busca, no fundo "confiamos" no caminho porque não sabemos o que pode ser encontrado. O "se deixar persuadir" é confiar no caminho e, no sentido mais simples, "obedecer à divindade"12 ou obedecer ao destino de buscar (o torna-te àquilo que és).

O outro caminho, "que não é e que não Ser necessário é", é explicado como sendo "totalmente inconhecível" ( $\left.\Pi \propto \nu \propto \pi \varepsilon \cup \theta_{\varepsilon}^{\prime} \alpha\right)$. Tal impossibilidade ocorre porque não se pode conhecer o "não sendo" ( $\mu$ ฑ่ દ̇òv) por não ser “terminável”. Diante dessa colocação, cabe aqui duas considerações. Uma diz respeito ao termo "necessário", que no início do comentário sobre os fragmentos de Parmênides, apontamos como sendo o mesmo que "necessita-se". Para Heidegger, a expressão significa "deixar entrar na essência e permanecer" ou em alemão "es braucht" (HEIDEGGER, 1984, p. 116). Isso implica dizer que o caminho do "não Ser e que não é" ao ser necessário, "necessita-se" ou chama a essência de algo. Ora, o "que não é e que não Ser", ao tornar-se "necessário" implica ativar um limite de interrupção fictícia para que possamos entender a noção que remete ao que não é em não Ser. Tal interrupção não é possível, por ser não terminável (sem termo) o "não sendo". O "não sendo", ao se dar por "necessidade" (isto é, "preciso"), é limitado ou posto a termo. Tal pensar, a deusa entende

\footnotetext{
${ }^{9}$ A expressão "circum-venīre" pode significar "vir, chegar em torno de, mostrar-se em torno de". (FARIA, 1962, p. 186 e 1052).

${ }^{10}$ Todos os termos entre aspas são definições do termo Пвí $\theta \omega$. (BAILLY, 2000, p. 1503-1504; LIDDELL, SCOTT, 1940, p. 1353-1354).

${ }^{11}$ No fragmento DK 28 B4, o sentido de desocultamento, que observamos na filosofia de Heidegger, é exposto.

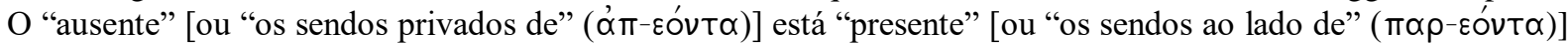
"ao intelecto" (vów), ou seja, na explicação daí derivada, o ocultamento e o desocultamento se co-pertencem. O não Ser indica que é, portanto, que existe. Se o não Ser existe, então deve existir o Ser porque o não Ser é.

${ }^{12}$ Não podemos esquecer que $\Pi \varepsilon ı \theta 0 u ̛$ sé também uma divindade, deusa da eloquência e da fidelidade.

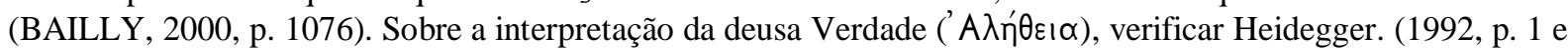
ss).
} 
como não conhecível e não dizível, porque o "não sendo" é ilimitado e interminável. Não há como fixar, parar, interromper o "não sendo".

Após a descrição dos "únicos caminhos", cabe entendermos as palavras que os descrevem. Um caminho diz que "não é em concreto" (oưk) e "não Ser em abstrato" ( $\mu$ ń) é e, outro, que "não é em concreto" (oưk) e que "não Ser em abstrato" ( $\mu$ ń) necessário é. Vemos com clareza a oposição da negação abstrata (ou do intelecto), relacionada ao pensar, confrontada a negação concreta (ou sensível), relacionada ao que é, ao vivenciado e perceptível. Ambas se copertencem e o resultado do pensar só é possível através disso. Parmênides apenas as separa para melhor explicar o que deseja dizer através da deusa. No

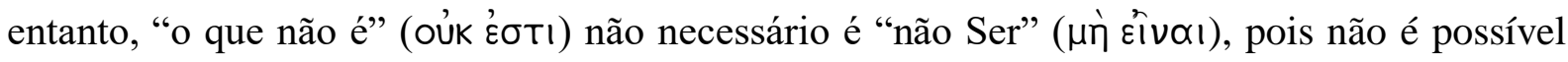
conhecer o "não sendo" ( $\mu \eta \zeta$ દò̀v) de forma necessária (a ser utilizada, plena, completa) porque o "sendo" (E’òv) é a conjugação do sensível e do inteligível em um único termo. Por ser um particípio (participium, $\mu \varepsilon т о \chi \eta ́$ ), o termo compõe o nome (o que é recolhido e depende das sensações somadas ou não aos desejos) e o verbo (aquilo que diz respeito à

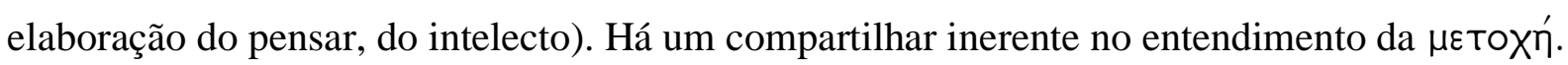
${ }^{13} \mathrm{O}$ çòv é o prenúncio sinalizador do que Aristóteles discute ao pensar o "Tí tò o"v" ("o que é o sendo em seu ser?"14) e do que Heidegger entendeu como Da-sein.

Em sentido diverso, Néstor L. Cordero (2005, p. 76) entende que

a substantivação do verbo 'ser' não significa em absoluto isso que os filósofos chamam 'o ser'. Para substantivar um infinitivo é necessário o fazer preceder de um artigo, neste caso, “o”. O infinitivo 'ser', então, transforma-se em 'o ser', em grego 'tò eînai'. Assim: esta fórmula nunca figurou entre as preocupações dos filósofos gregos.

Diante do entendimento do fragmento parmenídico, que expõe as diversas flexões do verbo ser, torna-se difícil concordar com Cordero. A chamada "substantivação" é compreendida semanticamente sem a necessidade de formalismos ou formulações. Parmênides expõe tal "substantivação" sem precisar de uma "fórmula". De certo modo,

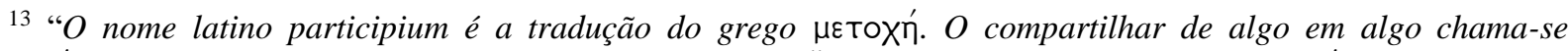

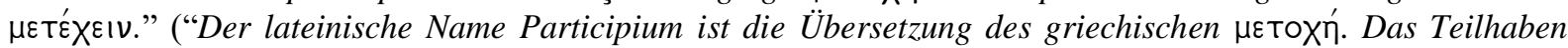
von etwas an etwas heißt $\mu \varepsilon \tau^{\prime} \varepsilon_{\chi} \varepsilon ı$ ”). (HEIDEGGER, 1984, p. 134). Para Heidegger, de algum modo, isto é possível: “A $\mu \varepsilon \dot{\varepsilon} \varepsilon \xi \xi \varsigma$, o compartilhar do sendo em o Ser, baseia-se nisso que gramaticalmente a $\mu \varepsilon$ To $\eta$ ń nomeia, ou seja, o particípio દ̇òv, óv." ("Die $\mu \dot{\varepsilon} \theta \varepsilon \xi ı$, die Teilhabe des Seienden am Sein, beruht in dem, was

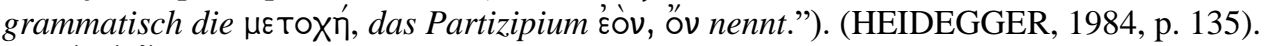

14 “тí tò óv, was ist das Seiende in seinem Sein?". (HEIDEGGER, 1984, p. 135). Trata-se da famosa expressão aristotélica, presente na Metafísica (1003a20): "тí tò ôv ṇ̂ov; quid est ens qua ens?". Com essa pergunta a filosofia delimita sua conclusão em seu início. (HEIDEGGER, 1961, p. 452).
} 
Cordero admite tal "substantivação" ao dizer, no caso do "particípio presente do verbo ser", que Parmênides evita o artigo "tò" ("o") "sempre que pode" (CORDERO, 2005, p. 76). Isso, indiretamente, já demonstra que "o ser" (Tò Eîvœı) foi pensado pelo filósofo de forma "substantivada" em seu fragmento. Não há como qualificar o entendimento de Heidegger como "imaginação transbordante", na forma qualificada por Cordero, no momento que verificamos como Parmênides semanticamente emprega o verbo no contexto do fragmento. $\mathrm{O}$ particípio e o infinitivo são diferenciados por Heidegger em suas análises. Parmênides não precisa empregar "tò ê̂nai" (Tò Ề @ı) expressamente para indicar a chamada "substantivação", basta simplesmente empregar "ê̂nai" (Tò દivœı) no fragmento.

Se não termos como claras as diversas flexões do verbo ser, não poderemos entender a mensagem de Parmênides. "Ser" (Êંvaı) difere de "sendo" ("̌ov, દóótos) e difere de "é"

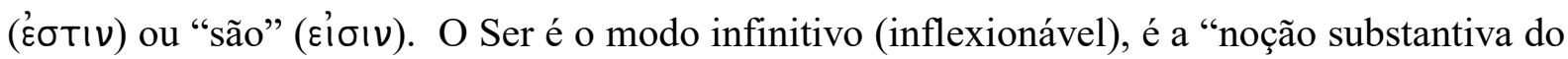
verbo" e "pode exercer todas as funções do substantivo" (MURACHCO, 2009, p. 29). Isso implica dizer que o Ser para os gregos é substantivado. O Ser é o próprio existir $\left({ }^{\prime} \xi \xi-\varepsilon \sigma \tau ו\right)$. O "sendo", por outro lado, é o modo particípio e outra "forma nominal do verbo". O particípio "sendo" é verbo mais nome (ou adjetivo). O verbo substantivado (ser) mais o nome (nas funções que o senso-comum chama de "sujeito" ou "objeto") reveste o sentido originário do particípio no grego antigo. O particípio neutro દóvтos, que testemunhamos grifado como દóv no fragmento de Parmênides, deriva de " $\varepsilon \sigma-O-\nu \tau-O S$ "15. O termo foi sofrendo transformações e sendo simplificado.

Tal entendimento das nuances do verbo ser permite a superação da tradicional discussão "dos multiplos significados do "é”" ("Die vielfache Bedeutung von „ist"” ). O verbo ser na $3^{\mathrm{a}}$. pessoa singular explicita-se como "é" ('̇oTıv). Não podemos entender a multiplicidade de significados, indicativa de esvaziamento do verbo, que existiria na separação em um “"é' existencial” (“Existentiales ,,ist“"), um “"é’ predicativo” (“Prädikatives , ist“") e um “"é' veritativo” (“Veritatives , ist"“") nos fragmentos de Parmênides (Cf. RAPP, 1997, p. 112-119). A compreensão do "é” em Parmênides indica que o Ser compreende o

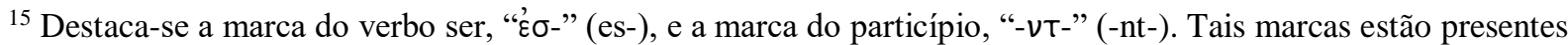
no verbo ser do latim (esse). O particío presente do verbo ser latino é "entis" (es-se-nt-is) ou, de modo simplificado, "ens". O "ente" é um substantivo derivado do particípio "entis". A marca "-nt-" ("-vт-"), que desapareceu com o tempo, está presente em "esse-nt-ia". A marca "-nt-" nas línguas modernas foi transformada em "-nd-", daí em português a palavra "sendo" e em alemão "Seiendes". O "ente" deriva de "ens" e coisificou a ação reflexiva do verbo, mantendo o nome como coisa (ente).
} 
próprio questionar o sentido daquilo que o explica. Portanto, para questionarmos o Ser precisamos do próprio ser, classificado aqui gramaticalmente como na $3^{\text {a }}$ pessoa do singular. ${ }^{16}$

O entendimento dessas flexões do verbo ser permite uma aproximação à explicação do primeiro caminho indicado pela deusa, isso observamos em outro importante fragmento do poema:

Frag. 2

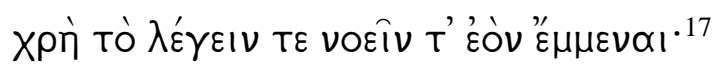

É necessário recolher [dizer] e pensar e Ser [existir] sendo.

Vemos aqui novamente surgir a questão, tratada por Heráclito, do pensar. Parmênides diz que "é necessário" (XpÍ) ou, como alertado por Heidegger, "necessita-se" ("precisa-se") ${ }^{18}$. O pensador afirma que "es brauchet" ("necessita-se") confunde-se com "es ist nötig" ("isto é necessário"; "isto é preciso"). O “é necessário" que deixa a essência aparecer é solicitado por algo. Esse "algo" é o "pensar" e o "dizer". O "pensar" ( voદî) que permite o "recolher" ou "deixar ver" ( $\left.\lambda \lambda^{\prime} \gamma \varepsilon ı\right)$ é o que o caminho faz desvelar e o que causa "espanto" e "admiração" ao poeta. O $\lambda \varepsilon^{\prime} \gamma \varepsilon ı$ é, portanto, o "deixar ser" ou "deixar-existir" "pensar" ou, para Heidegger, o "[em] tomar-cuidado" ("tomar-em-[a]-atenção") ${ }^{20}$. Esse "tomar" pode ser simplesmente o "ser tomado". O "tomar-atentamente" é em si o "recolher",

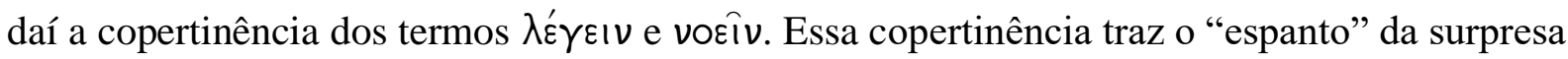
com o que permite pensar: "o Ser sendo". O "Ser sendo" é, em uma linguagem mais atualizada, o "existir do que é" ou o "ek-sistir do Dasein". Aqui nos aproximamos do que Heráclito almejava dizer (DK 22 B119). O "ek-sistir" é o já estar fora no transcender. O pensar já é o transcender. Algo “imponderável” para Heráclito e, por isso, maravilhoso. Esse transcender demonstra ser o mais essencial ao Dasein. O único "que é”, o único que pode ser dito como "sendo" ('́òv).

\footnotetext{
${ }^{16}$ Daí a afirmação de Heidegger, segundo a qual "O ser é o conceito mais universal e mais vazio" ("»Sein« ist der allgemeinste und leerste Begriff."). (HEIDEGGER, 2006, p. 2). Daí o sentido do Ser ser o mais compreensível e o mais desgastado, o mais dito e o mais esquecido.

${ }^{17}$ DIELS; KRANZ, 1951, p. 232. Existe discussões à respeito dos manuscritos de Simplício, em específico quanto ao primeiro "Tع", entendido como "Tò". (CORDERO, 2005, p. 213).

${ }^{18} \mathrm{Na}$ tradução de Heidegger: "Necessita-se: o deixar-existir e, por isso, (o) tomar-em-[a]-atenção, também o sendo, assim, o ser." (“»Es brauchet: das Vorliegenlassen und so (das) In-die-Acht-nehmen auch: Seiendes: sein. «"). (HEIDEGGER, 1984, p. 131).

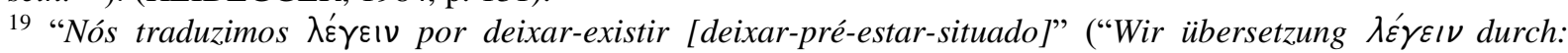
Vorliegenlassen"). (HEIDEGGER, 1984, p. 125).

20 "In-die-Acht-nehmen" (HEIDEGGER, 1984, p. 125).
} 


\section{$2 O$ sentido do éthos em parmênides}

Diante desses alertas, podemos tratar do questionamento que buscamos. O segundo

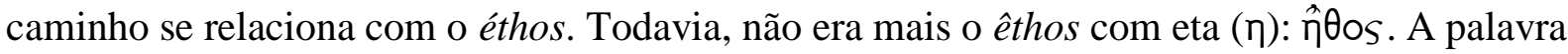
surge em seu pensar com a letra épsilon $(\varepsilon)$ : ' ${ }^{\prime} \theta 0 s$ (éthos). A transformação indica nova mudança. Outra forma de vivenciar o agir é denunciada. $\mathrm{O}$ fragmento é assim registrado:

Frag. 7

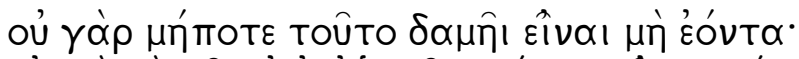

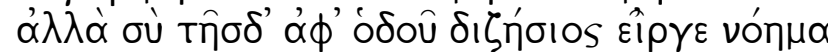

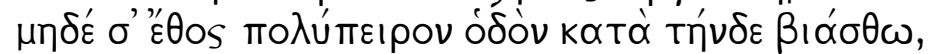

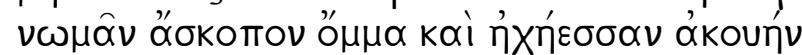

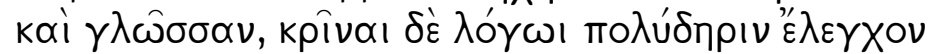

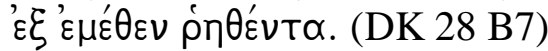

Pois não nunca se imponha isto: ser não sendo [sendos, que são];

Afasta tu o resultado do pensamento desta via (caminho) de investigação, e o in-

veterado costume não te force, ao longo deste caminho, a empregar

o olho que não vê, o ouvido que ressoa e a língua; julga através do recolher

a prova controversa que tem sido dita (lançada) a partir de mim. ${ }^{21}$

$\mathrm{O}$ ”ै'Oos aqui se delineia como um "costume" coletivo tradicional. Parmênides adverte quem o escuta a respeito do hábito encobridor que pode ocupar-se do segundo caminho

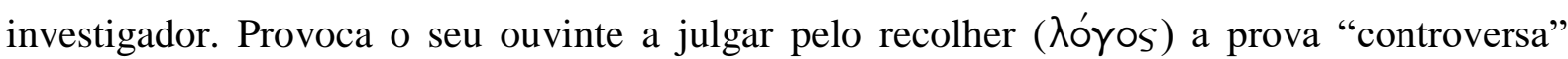
(polêmica) que lança. A prova controversa admite a oposição. Na oposição convive o argumento oposto. Portanto, há "coisas que são" e há "coisas que não são". Ao projetar essa prova controversa ao julgamento de quem ouve com atenção, deseja demonstrar que, ao existir o pensar sobre coisas que são e que não são, vigoram os contrários.

O hábito encobre o resultado do pensamento ( $v o ́ \eta \mu \alpha)$ e não faz ver, ouvir e falar sobre o que é. O caminho que se delineia não pode ainda se contentar com esse resultado do pensar. O hábito aparece como o que já comumente se faz sem se refletir sobre. O costume já está aqui arraigado ou profundamente enraizado. O habitual deixa de ser o sendo para ser a fixação da verdade. O hábito ou costume fixa a verdade e a faz perder o cárater dinâmico do

\footnotetext{
${ }^{21}$ A tradução é livre. O termo દóvta é particípio neutro plural, daí o sentido de "sendos, que são". Poderia ser traduzido por "entes", mas o termo traz o encobrimento que vincula a palavra "ente" a "coisa". Antes havíamos adotado, com algumas alterações, a compreensão gramatical de Néstor Luis Cordero. (CORDERO, 2005, p. 219).
} 
desencobrimento. A verdade se fixa como algo já garantido e certo. Nesse momento, o habitual perde a capacidade de se oferecer ao ser como medida e possibilidade de conservação do que é claro. O sentido da $\alpha^{\prime} \lambda \eta^{\theta} \theta \varepsilon ı \alpha$ é esquecido pelo velho costume. Por isso, recebe a crítica de Parmênides. O importante é perceber aqui como o "๕もos se encobriu em comparação com o sentido originariamente estabelecido seja em Homero seja em Heráclito.

Em Heráclito, o $\hat{\eta} \theta 0 s$, escrito com $e t a^{22}$, demonstra ser mais desencobridor. O sentido de habitar, morada e, finalmente, de agir, enquanto fixar-se em algo, permite, segundo Heidegger, o desvelamento dos entes. O $\hat{\eta} \theta 0 s$ mais próprio, no entender de Heidegger, é “o morar ou o viver (Wohnen) do ser humano, a morada ou a estada (Aufenthalt) em meio à totalidade dos entes [sendos]" (HEIDEGGER, 1994, p. 214). Esse modo de agir grego determina a compreensão do próprio sentido desse mesmo agir. O "sendo" é que eleva o Ser e o diferencia. Daí a frase: “ $O \hat{\eta} \theta 0 s$ é a atitude firme ou a compostura (Haltung) em todo comportamento ou conduta (Verhalten) dessa estada em meio ao ente [sendo]" (HEIDEGGER, 1994, p. 214). O agir deriva de habitar. Esse habitar, em outro modo, gera o hábito. O hábito seria uma forma de se manter e deixar ver o mundo (HEIDEGGER, 1972, p. 39-41). Esse "fixar-se" como "ater-se" do ser humano determina como ele pode se comportar diante dos demais entes ou "sendos" (colhendo o seu sentido). O ser age em $\hat{\eta} \theta 0 s$ e através do mesmo ("im $\hat{\eta} \theta$ os und durch es"). Esse "achar-se junto a" ao "fixar-se em" é também acolher ou conviver, entendido como co-pertinência.

\section{Considerações finais}

A diferença entre o " $\varepsilon^{\prime} 0$ os parmenídico e o $\hat{\eta} \theta 0 s$ heraclitiano foi muito pouco explorada pelos estudiosos do chamado período "pré-socrático". Apesar de Heidegger não ter se ocupado, ao menos diretamente, da desfiguração do termo, podemos verificar que muito pode ser extraído de sua aproximação sobre o $\hat{\eta} \theta$ os heraclitiano e grego em geral.

$\mathrm{O}$ ’’もos parmenídico é já um hábito transfigurado em vício ou erro. Junto a ele, age-se como a maioria ou aqueles que não pensam mais sobre os sentidos do ser e da verdade. É um hábito, mas um hábito encobridor. Ao não pensar, os seres não são capazes de discernir a via da verdade. Muito provavelmente foi inspirado em Parmênides que Heidegger chega a visão

\footnotetext{
${ }^{22}$ Como ocorreu, p. ex., em Homero e Hesíodo. (PROSCURCIN JUNIOR, 2014, p. 160 e ss).
} 
diferenciada do Dasein, caracterizando-o como o ser que possui a capacidade de pensar ao agir, diferenciando-se de todos os demais entes. Parmênides provoca os seus leitores a pensar.

Em Heráclito vemos, no entanto, outro modo de agir vinculado ao termo grifado com eta ( $\hat{\eta} \theta 0 \varsigma$ ). Naturalmente, esse agir no, e através do $\hat{\eta} \theta$ os é o diferencial que caracteriza o ser vivo (Lebewesen) em sua postura junto aos demais entes (sendos) como um todo. Nesse âmbito a filosofia de Heidegger soube bem explorar o sentido mais autêntico do termo.

Diante do $\hat{\eta} \theta o s$, o ser que somos (Dasein) pode buscar a compreensão "do sendo em sua totalidade" (...des Seienden im Ganzen) (HEIDEGGER, 1994, p. 217). Nesse sentido, Heidegger elucida: "Por isso, poderíamos dizer, justificadamente, que o ser humano (der Mensch) é aquele ente [sendo] dentro do ente em seu todo [na totalidade] (...Seiende

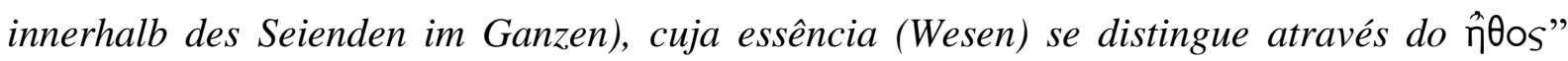
(HEIDEGGER, 1994, p. 217). O "ente em seu todo" (in toto) configura-se como a composição de cada um dos entes que formam um agregado de diversos entes (Seienden; દóvta). Dentro desse todo está cada um dos seres humanos enquanto "̌ov. O ser humano enquanto um ente especial (um sendo ou agentes que é) possui uma essência que o diferencia. $\mathrm{O} \hat{\eta} \theta$ os é, deste modo, o que distingue o ser humano dos demais entes. Aqui se estabelece o mais importante à compreensão do termo. O $\hat{\eta} \theta$ os é a essência do Dasein. Sendo essência é o ser mais próprio do ser humano. Ao ser o que o distingue dos demais entes, o $\hat{\eta} \theta$ os se posiciona como o mais importante. O $\hat{\eta} \theta$ os não é mero caráter ou hábito. Desvela-se como agir cuja essência o distingue dos demais entes. Esse agir que distingue o $\hat{\eta} \theta$ os dos demais entes é o Ser. O agir para os gregos é Ser. Como o agir mais importante é o pensar (voદiv) que reflete esse mesmo agir (DK 28 B3). Pensar sobre o agir é o que distingue o ser humano grego. Pensar sobre o agir é, nesse sentido, pensar sobre o Ser. Pensar sobre o Ser é já "eksistir". O "ek-sistir", como o transcender do pensar, do agir é o "Ser do sendo". É o que distingue o Dasein dos demais entes.

\section{Referências}

BAILLY, Anatole. Le grand Bailly: dictionnaire grec français. L. Séchan e P. Chantraine (revs.). Paris: Librairie Hachette, 2000.

CORDERO, Néstor Luis. Siendo, se es. Buenos Aires: Biblos, 2005.

DIELS, H.; KRANZ, W. Die Fragmente der Vorsokratiker. Vol. 1, 6th ed. Berlin: Weidmann, 1951. 
FARIA, Ernesto (Org.). Dicionário escolar latino-português. 3 ed., Rio de Janeiro: MEC, 1962.

HEIDEGGER, Martin. Nietzsche. Erster Band, Pfullingen: Neske, 1961.

HEIDEGGER, Martin. Über den Humanismus. Frankfurt am Main: Vittorio Klostermann, 1972.

HEIDEGGER, Martin. Was heißt denken? Tübingen: Max Niemeyer, 1984.

HEIDEGGER, Martin. Parmenides. Bd. 54, Frankfurt am Main: Vittorio Klostermann, 1992.

HEIDEGGER, Martin. Heraklit. Bd. 55, 3 ed., Frankfurt am Main: Vittorio Klostermann, 1994.

HEIDEGGER, Martin. Sein und Zeit. 19 ed., Tübingen: Max Niemeyer, 2006.

HOMERO. Odisseia. Tradução de Carlos Alberto Nunes. Rio de Janeiro: Ediouro, 2001.

LIDDELL, Henry George; SCOTT, Robert. A Greek-English Lexicon. Oxford: Clarendon Press, 1940.

MURACHCO, Henrique Graciano. Língua grega: visão semântica, lógica, orgânica e funcional. Vs. 1 e 2, São Paulo: Vozes, 2003.

NAZARI, Oreste. Dialetto Omerico: grammatica e vocabolario. Torino: Chiantore, 1952.

PROSCURCIN JUNIOR, Pedro. Der Begriff Ethos bei Homer. Heidelberg: Winter, 2014.

RAPP, Christof. Vorsokratiker. München: Verlag C. H. Beck, 1997. 